\title{
Severe wear behaviour of alumina balls sliding against diamond ceramic coatings
}

\author{
ANURADHA JANA ${ }^{1,2}$, NANDADULAL DANDAPAT ${ }^{1}$, MITUN DAS ${ }^{1}$, VAMSI KRISHNA BALLA ${ }^{1}$, \\ SHIRSHENDU CHAKRABORTY ${ }^{1}$, RAJNARAYAN SAHA ${ }^{2}$ and AWADESH KUMAR MALLIK ${ }^{1, *}$ \\ ${ }^{1}$ CSIR-Central Glass \& Ceramic Research Institute, Kolkata 700032, India \\ ${ }^{2}$ Department of Chemistry, National Institute of Technology, Durgapur 713209, India
}

MS received 16 July 2015; accepted 3 November 2015

\begin{abstract}
At present alumina is the most widely used bio-ceramic material for implants. However, diamond surface offers very good solid lubricant for different machinery, equipment including biomedical implants (hip implants, knee implants, etc.), since the coefficient of friction (COF) of diamond is lower than alumina. In this tribological study, alumina ball was chosen as the counter body material to show better performance of the polycrystalline diamond (PCD) coatings in biomedical load-bearing applications. Wear and friction data were recorded for microwave plasma chemical vapour deposition (MWCVD) grown PCD coatings of four different types, out of which two samples were as-deposited coatings, one was chemo-mechanically polished and the other diamond sample was made free standing by wet-chemical etching of the silicon wafer. The coefficient of friction of the MWCVD grown PCD against $\mathrm{Al}_{2} \mathrm{O}_{3}$ ball under dry ambient condition was found in the range of $0.29-0.7$, but in the presence of simulated body fluid, the COF reduces significantly, in the range of $0.03-0.36$. The samples were then characterized by Raman spectroscopy for their quality, by coherence scanning profilometer for surface roughness and by electron microscopy for their microstructural properties. Alumina balls worn out $\left(14.2 \times 10^{-1} \mathrm{~mm}^{3}\right)$ very rapidly with zero wear for diamond ceramic coatings. Since the generation of wear particle is the main problem for load-bearing prosthetic joints, it was concluded that the PCD material can potentially replace existing alumina bio-ceramic for their better tribological properties.
\end{abstract}

Keywords. Alumina; diamond; ceramic coatings; tribology.

\section{Introduction}

Diamond is an excellent allotrope of carbon with $\mathrm{sp}^{3}$ hybridized electronic orbitals forming a crystalline unit cell of two close packed interpenetrating face centred cubic lattices. Diamond is the most impressive material among all, as it has exceptional properties like highest hardness, chemically inertness, wear resistance with a very low coefficient of friction, optical transparency from UV to far IR range, high thermal conductance, electrical insulation and bio-compatibility [1]. Tribology is a relatively new science that considers the friction, wear and lubrication of moving contacts [2-4]. Adhesion, friction and wear are the main factors of tribology of contacting or sliding interfaces. The science is applied in various industries like mining, automotive, food, nuclear, offshore, marine and biomedical, etc. The materials which are used in tribology face continuous mechanical wear as well as chemical leaching due to corrosive media or environment and face the severity of tribo-corrosion [5]. The other after effects are the corrosion with solid particle erosion, abrasion, cavitation erosion, fretting, biological corrosion, sliding wear and tribo-oxidation. The wear debris from such tribological

\footnotetext{
*Author for correspondence (amallik@ cgcri.res.in)
}

materials also increases the rate of overall tribo-corrosion. As a result, the equipment gets damaged before the expected date of expiry. Existing orthopaedic polymer, metal and ceramic materials being used in the biomedical industry also face the problem of tribo-corrosion due to mechanical wear. The generated wear debris is the precursor of osteolysis, where the bone part is damaged and leached out due to interaction with the particles from an implant material and as a result the loosening of transplant occurs. The solution to the unexpected failures of machinery parts or implants is the use of new promising materials or coating which not only reduces the problem of tribo-corrosion but also prolongs the machine life [6]. Diamond has been chosen for ideal tribological material, as it has remarkable mechanical properties which have already been outlined [7]. Biomedical implants like hip and knee joints are also exposed to sliding movements, which eventually wear out the contacting surfaces. To prevent osteolysis from wear debris particles, it is recommended to use low wear material for bio-implants. Earlier metal-on-metal or metal-on-ceramic or ceramic-on-polymer articulating combinations had been tried as load-bearing implants, but it was found that none of them could provide an acceptable amount of wear debris generation, which could initiate osteolysis inside the human body. Nowadays the material of choice for the state-of-the-art load-bearing 
implants is the alumina-on-alumina tribo-couple with ultra low wear rate. But even they come with the problem of brittle fracture if the implant size is big enough to cause crackinitiated catastrophic failures. Here we propose that if (i) such alumina material can be replaced with further low wear rate material like diamond and (ii) instead of bulk ceramic if the diamond is used onto the load-bearing implants as thick coating, then possibly both the problems associated with the present day tribo-couples can be overcome, namely, wear debris generation and their brittle fractures. The aim of our present study is to know the suitability of polycrystalline diamond (PCD), if this ceramic coating can be used, for example, in hip prosthesis, instead of existing alumina ceramic. PCD coating on the acetabular cup and femoral head may replace/supplement the existing alumina materials, to prolong the implant life and also may prevent the unnecessary formation of wear debris, as harder PCD coating has very low coefficient of friction and it is chemically inert $[8,9]$. Biocompatibility and non-toxic effect on cells by PCD surface [10-13] also are the advantages of choosing diamond coating as a new material for future implants to get rid of the problem of tribo-corrosion [14]. From the literature study of the tribological behaviour of diamond surface, it is verified that diamond has very low coefficient of friction. In normal atmospheric and humid condition diamond surface shows very low COF, but in ultrahigh vacuum (UHV) $\mathrm{COF}$ was found to be much greater. Adsorption of gaseous species such as water, oxygen and other gases on the surface makes diamond a good solid lubricant. Very low 0.02 $0.04 \mathrm{COF}$ with a very low wear rate of $10^{-7}$ to $10^{-8} \mathrm{~mm}^{3}$ $\mathrm{Nm}^{-1}$ were observed in pin on disk study with a natural bulk diamond pin and diamond surface. Under ultrahigh vacuum, diamond COF increases to $1.5-1.7$, and wear rate also increases to $10^{-4} \mathrm{~mm}^{3} \mathrm{Nm}^{-1}$ [15]. At $10 \%$ relative humidity, diamond counter face rubbed against a diamond surface shows very low $\mathrm{COF}$ value below 0.1 with a negligible wear rate of $10^{-16} \mathrm{~mm}^{3} \mathrm{Nm}^{-1}$, whereas sapphire counter face sliding against the same surface showed slightly increased $\mathrm{COF}$ value [16]. Microwave plasma chemical vapour deposition (MWCVD) diamond surface sliding against a corundum ball shows smaller COF 0.05, whereas hot filament deposited CVD diamond shows COF value 0.1 at $50 \%$ relative humidity and $20^{\circ} \mathrm{C}$ temperature condition [17]. When the experiment was done with a $\mathrm{Si}_{3} \mathrm{~N}_{4}$ counter face on the diamond surface at 50-60\% relative humidity, relatively higher COF 0.7 was detected with a wear rate of $10^{-7} \mathrm{~mm}^{3} \mathrm{Nm}^{-1}$ [18]. In another experiment, $\mathrm{Si}_{3} \mathrm{~N}_{4}$ counter face was used against diamond coated $\mathrm{SiC}$ surface and the relative humidity was $43 \pm 2 \%$ at $25 \pm 2{ }^{\circ} \mathrm{C}$ temperature, which showed COF values between 0.55 and 0.1 [19]. When the nanocrystalline diamond surface was used against $\mathrm{Si}_{3} \mathrm{~N}_{4}$ counter face, lower COF 0.1 value was obtained in air than $\mathrm{COF}$ value 0.5 in $\mathrm{N}_{2}$ [20]. Under the dry and humid conditions, (50-60\% relative humidity) COF value was approximately 0.05 for diamond against a diamond surface [21]. Partly polished diamond coatings in ambient air at room temperature against steel bearing balls show COF value of 0.09 [22], whereas under vacuum condition steel ball against PCD surface shows COF value of 0.53 [23].

All the above-cited values are for self-mating surfaces or for diamond against some metal or ceramic counter bodies. Surprisingly, there is not much literature available for alumina balls sliding against diamond ceramic coatings. Bhushan et al [24] reported tribological properties of HFCVD grown diamond when slid against alumina balls. They found the coefficient friction was as high as 0.4 for unpolished films, whereas chemo-mechanically polished and lubricated diamond films showed somewhat lower COF values. Moreover, they reported that both the alumina and diamond film worn out under sliding action, which may be due to the inferior quality of PCD coatings used [24]. Nanocrystalline diamond-coated cemented carbide showed 0.8 COF when slid against alumina pins [25]. Skopp and Klaffke [26] did some tribological tests of diamond coatings with steel and alumina balls, but they carried out the tests under unlubricated and vibrating contact with varying humidity at room ambience. They observed severe wear and friction during running in period for the alumina balls but with negligible friction $(<0.05)$ and almost zero wear afterwards-a complete contradiction to the authors' present findings. In another article, researchers have reported extremely low wear and friction of diamond coated with Ti6Al4V for fretting action against alumina [27]. Although there are so many research articles on tribological behaviour of diamond-like carbon films [28] at different environments, there are not enough articles specifically reporting ball on disk experiments with PCD coatings against alumina balls. 'Diamond alumina tribology' search results at the website www. scholar.google.com could only show 2-3 articles specifically describing diamond-alumina tribo-couple. One of them reported super low value of friction coefficient $(\sim 0.003)$ and extremely high wear resistance $\left(\sim 2.8 \times 10^{-21} \mathrm{~mm}^{3}\right.$ $\mathrm{Nm}^{-1}$ ) when the $\mathrm{Al}_{2} \mathrm{O}_{3}$ ball slid against nanocrystalline diamond nanowire film [29]. Another search result describes tribological characteristics in high-speed grinding of alumina with brazed diamond wheels [30]. However, none of them particularly reports tribo-couple which is being discussed below.

In the present study tribology experiments were done with MWCVD PCD surface against alumina ball in dry ambient (room temperature $25^{\circ} \mathrm{C}$ and relative humidity 50\%) and stimulated body fluid (SBF) media condition. The ion concentration of SBF was almost the same as the human blood plasma. The reason for choosing SBF as one of the experimental conditions was to study the suitability of PCD coating as a bio-tribological material. The very smooth nucleation side of freestanding diamond coating, chemo mechanically polished very thin coating and as-grown samples were used for evaluating wear and friction against alumina counter body. The reason for choosing alumina as the counter body is because $\mathrm{Al}_{2} \mathrm{O}_{3}$ is the most widely used ceramic material used in a bio-tribological application like load-bearing implants. Alumina-on-alumina is the state-of-the-art loadbearing implant for orthopaedic application, due to their ultra 
low wear rate. If any other material is found to produce less wear rate than alumina, then it has the potential to replace alumina as a material of choice for bio-implants. It is here to investigate the better performance of PCD over alumina ceramics under biological conditions.

\section{Materials and methods}

\subsection{Processing of PCD coatings}

MWCVD reactor (DT1800, Lambda Technologies Inc., USA) was used to deposit good quality PCD, as this type of reactor has no filament, cathode or anode components inside the chamber which may increase the probability of contamination in the growing diamond film. Microwave-assisted deposition of CVD diamond depends on the geometry of the cavity, such as stage height, short length, probe length, diameters of the cavity. The other processing parameters like microwave power, process gas flow, pressure, substrate temperature, etc. also have significant roles in controlling plasma deposition on the substrate surface [31]. The four samples namely W11, W13, W14 and W23 have been selected for the present study. The deposition parameters are listed in table 1.

Microwave power was set at $9 \mathrm{~kW}$ and the probe height was fixed at $8.7 \mathrm{~cm}$ during the microwave plasma deposition. Different parameters like gas flow rate, pressure, short height, stage height and temperature inside the plasma chamber were slightly changed during every deposition of the CVD diamond coating. Deposition time was also varied from sample to sample, due to which the thickness of the each deposited sample was also found to be different. For W11 sample, gas flow rates of $\mathrm{CH}_{4} / \mathrm{H}_{2}$ were 5/500 standard cubic centimetre per minute ( $\mathrm{sccm})$. Plasma chamber was kept at a pressure of 118 Torr with substrate temperature within 970$1070^{\circ} \mathrm{C}$. Short and stage heights were set at 58.6 and $0.9 \mathrm{~cm}$, respectively. For W11 sample, PCD coating was very thick as the deposition time was 239 h. On the other hand, W13 sample was deposited only for $9 \mathrm{~h}$ and the gas flow rates of $\mathrm{CH}_{4} / \mathrm{H}_{2}$ gases were $25 / 1000 \mathrm{sccm}$. The pressure of the plasma chamber was kept at 110 Torr and the substrate temperature was fluctuating between 985 and $1065^{\circ} \mathrm{C}$ with stage and short heights at 0.5 and $58.2 \mathrm{~cm}$, respectively, for W13. Similarly, deposition time for W14 sample was short, only $7 \mathrm{~h}$, and the $\mathrm{CH}_{4} / \mathrm{H}_{2}$ gas flow rates were $10 / 1000$ sccm at plasma chamber pressure of 110 Torr. Inside the plasma chamber, short and stage heights were at 58.5 and $0.2 \mathrm{~cm}$, respectively, and the substrate temperature was kept in between 864 and $1067^{\circ} \mathrm{C}$ (the widest temperature spectrum due to high surface thermal instability) in the case of W14. For W23 sample, $\mathrm{CH}_{4} / \mathrm{H}_{2}$ gas flow rates were at 20/1000 sccm. Inside the plasma chamber, the pressure was 106 Torr and the substrate temperature was maintained at 900$1000^{\circ} \mathrm{C}$. Again short and stage heights were slightly changed to 58.3 and $0.3 \mathrm{~cm}$, respectively. Deposition time for W23 sample was $25.5 \mathrm{~h}$. These four PCD samples were deposited with different methane concentrations, which thereby change the quality of each diamond coatings. If the methane concentration increases in the precursor gas, then the amount of $\mathrm{sp}^{2}$ carbon or amorphous carbon present inside the deposited diamond also increases and thereby degrades the quality of the deposited coating [32-34]. All the CVD growth parameters were almost identical, except the methane percentages and the depositions times, which resulted in differential quality and thickness among the deposited PCDs.

After deposition of CVD diamond on the silicon wafers, W13 and W23 samples were not processed further. W14 sample was chemo-mechanically polished for several hours in CETR make CP4 (USA) polishing machine, using diamond-coated polishing disk with $1 \mu \mathrm{m}$ diamond suspension slurry. PCD coating was very hard and polishing of the as-deposited diamond surface was very challenging. Chemo-mechanical polishing is one of the popular polishing techniques of thin diamond coatings $[35,36]$. Chemical wet etching was done for the W11 diamond coating to remove the base substrate for getting the free standing diamond coating. Silicon base substrate was etched out by using hydrofluoric acid $(\mathrm{HF})$, nitric acid $\left(\mathrm{HNO}_{3}\right)$ and acetic acid $\left(\mathrm{CH}_{3} \mathrm{COOH}\right)$ in the 1:1:1 volume ratio [37]. Thus, four different PCD surfaces were created to test the tribological behaviour against alumina ceramic balls.

\subsection{PCD Characterizations}

PCD was deposited on $100 \mathrm{~mm}$ diameter silicon wafers but for further studies the wafers were broken into smaller pieces. The roughness of the sample depends on the deposition time and the growth of the diamond nuclei on silicon substrate surface. Deposited diamonds on substrate surface were polycrystalline in nature containing troughs and valleys. Different PCD roughness at different locations on the same wafer surface was observed due to the presence of random asperities on PCD surface. Average roughness (Ra) was measured by using the coherence scanning interferometer (CSI) (Contour GPK, Bruker, Germany). In coherence scanning interferometer, optical lens scans wide $\left(0.6 \times 0.8 \mathrm{~mm}^{2}\right)$

Table 1. Deposition parameters of the polycrystalline diamond coatings on the silicon wafers.

\begin{tabular}{|c|c|c|c|c|c|c|c|c|c|}
\hline $\begin{array}{l}\text { Sample } \\
\text { name }\end{array}$ & $\begin{array}{l}\text { Deposition } \\
\text { time }(\mathrm{h})\end{array}$ & $\begin{array}{c}\mathrm{H}_{2} \\
\text { flow }(\mathrm{sccm})\end{array}$ & $\begin{array}{c}\mathrm{CH}_{4} \\
\text { flow }(\mathrm{sccm})\end{array}$ & $\begin{array}{l}\text { Pressure } \\
\text { (Torr) }\end{array}$ & $\begin{array}{c}\text { MW power } \\
(\mathrm{kW})\end{array}$ & $\begin{array}{l}\text { Probe length } \\
\qquad(\mathrm{cm})\end{array}$ & $\begin{array}{l}\text { Short height } \\
(\mathrm{cm})\end{array}$ & $\begin{array}{l}\text { Stage height } \\
(\mathrm{cm})\end{array}$ & $\begin{array}{c}\text { Substrate } \\
\text { temperature }\left({ }^{\circ} \mathrm{C}\right)\end{array}$ \\
\hline W11 & 239 & 500 & 5 & 118 & 9 & 8.7 & 58.6 & 0.9 & $970-1070$ \\
\hline W13 & 9 & 1000 & 25 & 110 & 9 & 8.7 & 58.2 & 0.5 & $985-1065$ \\
\hline W14 & 7 & 1000 & 10 & 110 & 9 & 8.7 & 58.5 & 0.2 & $864-1067$ \\
\hline W23 & 25.5 & 1000 & 20 & 106 & 8.5 & 8.7 & 58.3 & 0.3 & 900-1000 \\
\hline
\end{tabular}


area of the PCD coated surface, and then takes an average of all the high asperities and the low asperities with a centre line. Raman spectroscopy (STR500, Technos Instruments, originally from Seki Technotron, Japan) of the samples were done to know the quality and stresses present in the diamond coating. Raman spectroscopy is a very popular investigative techniques for thin diamond coatings as it is simple, cheap and does not damage any mechanical properties of the coatings $[38,39]$. In Raman scattering, monochromatic laser light of wavelength $514.5 \mathrm{~nm}$ was used for the study of diamond-coated samples. A small proportion of phonons from this laser beam was absorbed by PCD crystals and then some portion of light was scattered inelastically by the vibrational excitation of crystals [40]. In natural diamond a single sharp peak is observed at $1332 \mathrm{~cm}^{-1}$. However, the synthetic diamond coatings prepared by CVD process gives Raman peaks nearer to it, because in PCD coatings there may be some imperfections present due to thermal stresses and non-diamond impurities. These non-diamond phases generally give the hump around $1450-1600 \mathrm{~cm}^{-1}$. The intrinsic stresses present in the PCD crystals are of compressive or tensile in nature. Compressive stress gives up-shift of the Raman peak and on the other hand, tensile stress gives down shift of the Raman peak [41,42]. The residual stress $(\Upsilon)$ is calculated in GPa using the following formula [43].

$$
\Upsilon=-0.567 \times \Delta \mathrm{U},
$$

where $\Delta \mathrm{U}$ is the peak shift in $\mathrm{cm}^{-1}$.

The quality factor $(Q)$ was calculated for the coated growth surface of the PCD coatings by using the following formula [44].

$$
Q=\left(\frac{I_{\mathrm{d}}}{I_{\mathrm{d}}+I_{\mathrm{glc}}}\right) \times 100 \%,
$$

where $I_{\mathrm{d}}$ is the intensity of the sharp diamond peak and $I_{\mathrm{glc}}$ is the intensity of the graphite-like carbon broad peak.

\subsection{Tribology}

The tribometer assembly (NANOVEA tribometer) was used for highly accurate and repeatable wear friction testing in rotational modes. In the experiments, rotational speed was varied from 50 to $200 \mathrm{rpm}$. A heating arrangement was also available to provide controlled liquid heating. The counterface was alumina ball, which was attached to a load arm, and the load arm was directly in contact with the experimental PCD disk surface. The experimental parameters for the tribological tests are given in table 2.

Table 2. Experimental parameters of the tribology tests.

\begin{tabular}{lcccr}
\hline & \multicolumn{3}{c}{ Experimental environments } \\
\cline { 2 - 5 } Parameter & \multicolumn{2}{c}{ Dry } & \multicolumn{2}{c}{ SBF } \\
\hline RPM & 50.9 & 76.3 & 95.4 & 191 \\
Load (N) & 3 & 1 & 3 & 1 \\
Radius of circular track (mm) & 7.5 & 5 & 4 & 2 \\
\hline
\end{tabular}

A 3-mm diameter ball was rotated along a circular path. Speed of the ball was fixed at $40 \mathrm{~mm} \mathrm{~s}^{-1}$ and also the travelling distance was set at $500 \mathrm{~m}$. In the tribology experiments, the environment, its applied load, the radius of the circular track and the rpm value were the changing parameters and table 2 shows how the parameters were varied. At the starting of the experiment, a $5 \mathrm{~N}$ load was applied and the distance of travel was set at $1000 \mathrm{~m}$ circular path with $7.5 \mathrm{~mm}$ radius for W13 sample in ambient air environment. After travelling 511 $\mathrm{m}$ distance, the experiment was aborted as the alumina ball was extremely worn out and the steel load arm was almost touching the rough PCD surface, which could have damaged the steel fixture of the experimental setup. To avoid any damage to the machine from the very hard polycrystalline articulating PCD surface, it was decided to limit the distance of travel to $500 \mathrm{~m}$ only. Further, the load was also reduced from $5 \mathrm{~N}$ to a lower load value of $2 \mathrm{~N}$, which again found to avoid any potential damage to the steel fixture during tribological experiment against the hard PCD surface. It was observed that the $2 \mathrm{~N}$ load did not severely wear the alumina balls, so $3 \mathrm{~N}$ and $1 \mathrm{~N}$ loads were selected for consecutive tribological studies. One set of tribology tests were done under the normal ambient condition without any lubricant i.e., dry with $25^{\circ} \mathrm{C}$ room temperature at $50 \%$ relative humidity. Another set of tribology experiments were carried out in SBF environment at $37^{\circ} \mathrm{C}$. The reason for choosing two different environments was to know the performance of PCD coating as bioimplants, since SBF has almost similar ion concentration like blood plasma. The radius of the revolutions and the value of the applied loads were varied for different PCD samples at dry and SBF conditions. As the travelling distance and speed of alumina ball did not change but only the radius of the circulating path was varied, so in effect, the revolution per minute was different in each case. Different rpm had the significance of differential contacts between articulating surfaces. In normal air environment, two radii of circular path were chosen and they were 7.5 and $5 \mathrm{~mm}$, respectively. Similarly, under SBF environment, two radii were 4 and $2 \mathrm{~mm}$, respectively. As the radius was decreased from 7.5 to $2 \mathrm{~mm}$, the rpm correspondingly increased from 50 to 190, in other words, the two articulating surfaces made more number of contacts while sliding, which can have tribological implications.

The optical microscope (Olympus BX 51) study was done after each tribological experiment to know the reduced radius of the worn out alumina balls. Wear volume of alumina ball was calculated by measuring the diameter of alumina ball after wear test. Further, the wear rate has been calculated from the volume of the worn out alumina ball.

$$
\begin{aligned}
& V=\frac{1}{3} \pi h^{2}(3 R-h), \\
& h=R-\sqrt{R^{2}-a^{2}},
\end{aligned}
$$

where $R=$ radius of alumina ball, $h=$ height from wear surface, $a=$ radius of wear surface and $V=$ volume of wear. 
So the wear rate is calculated from the volume of wear $(V)$ using the following equation.

$$
\text { Wear rate }=\frac{\text { Wear volume }}{\mathrm{Nm}} \text {, }
$$

where $N=$ applying load and $m=$ travelling distance.

The surface morphology and elemental analysis of the PCD coating were performed by scanning electron microscope (SEM) system (Phenom Pro X) at 5-15 kV beam energy.

\section{Results and discussion}

\subsection{PCD characterizations}

3.1a Roughness: The roughness of the PCD surface depends on the CVD deposition parameters. It increases with the increase of the deposition time. As the deposition time of the W11 sample was the highest, the roughness was also found to be the highest on its as-grown surface $(4-5 \mu \mathrm{m})$, but in the present tribological experiments, smooth nucleation side was selected by chemical etching of W11 PCD-coated silicon substrate. Very rough surface was intentionally avoided for carrying out any meaningful tribological study. Other PCD samples, namely W13, W14 and W23 show higher roughness than W11 nucleation side, according to their respective deposition timings. The roughness of the W14 sample was lower than the other samples because of its lower deposition time $(7 \mathrm{~h})$ and it was also chemo-mechanically polished. Similarly, the roughness of W23 sample was higher than W13 due to the higher deposition time $(25.5 \mathrm{~h})$ of W23 sample than W13 sample $(9 \mathrm{~h})$. Roughnesses of all the samples are tabulated in table 3.

The tribological study was done on the nucleation side of the sample W11, on the chemo-mechanically polished surface of W14 and on the as-grown surfaces of W13 and W23.

As the nucleation side was comparatively smooth, its surface roughness was small for both the W11 experimental pieces i.e., only 0.21 and $0.12 \mu \mathrm{m}$ for dry and SBF experiments, respectively. Roughnesses of the two pieces of W13 were 0.96 and $0.76 \mu \mathrm{m}$ under SBF and dry conditions, respectively. It was found that the roughness values of W14 pieces were 0.52 (SBF) and $0.49 \mu \mathrm{m}$ (dry). W23 sample shows roughness of $1.02(\mathrm{SBF})$ and $0.9 \mu \mathrm{m}$ (dry). W14 sample was chemo-mechanically polished so its roughness

Table 3. Average roughness of the PCD samples before wear study at dry and SBF environments.

\begin{tabular}{lcc}
\hline & \multicolumn{2}{c}{$R_{\mathrm{a}}(\mu \mathrm{m})$} \\
\cline { 2 - 3 } Sample name & Dry & $\mathrm{SBF}$ \\
\hline W11 & 0.21 & 0.12 \\
W13 & 0.76 & 0.96 \\
W14 & 0.49 & 0.52 \\
W23 & 0.9 & 1.02 \\
\hline
\end{tabular}

values of the two pieces were close to each other (planarization). Surface characteristics for other PCD samples were filled with troughs and valley only, but W23 sample had taller asperities than W13 as deposition time of W23 was higher than W13. W13 and W14 samples had comparable deposition timings, which might have produced similar surface roughness, but due to chemo-mechanical polishing of the W14 wafer, it shows lower $R_{\mathrm{a}}$ value than W13.

3.1b Quality and stress: Four types of samples were deposited with different $\mathrm{CH}_{4}$ flow percentages and different deposition times. The quality and stress present inside the diamond samples have been measured from Raman peak shift as shown in figure 1. It was found that the quality of the diamond coating decreases with increase in $\mathrm{CH}_{4}$ concentration. The quality of W11 and W14 samples were almost same since identical $\mathrm{CH}_{4}$ percentage (1\%, table 1) had been used. On the other hand, the quality of the W13 sample $(2.5 \%)$ was not better than W23 sample (2\%) due to usage of higher $\mathrm{CH}_{4}$ percentages (table 1). Mallik et al [45] had studied that the quality of PCD coating deteriorates with an increase of the $\mathrm{CH}_{4}$ percentage on $\mathrm{H}_{2}$. Residual stress arises in the PCD coating due to thermal expansion coefficient mismatch with the base silicon substrate [46]. It is found that W11, W13 and W14 samples have similar tensile stress present in the regions where the Raman signals were taken from. The tensile stress arises due to growth defects like dislocation, vacancy, twin, etc. present inside the growing crystals. Identical values of the stress indicate that there was an identical down shift of the Raman peak in the signals from the diamond coating. To explain this similar down shift, it would be interesting to note that W13 and W14 samples were grown for very less number of hours. But on the other hand, W11 was grown for almost 10 days. Although W11 was grown for $239 \mathrm{~h}$, the Raman signals were taken from the nucleation side of the freestanding coating. The nucleation side after removal of the base substrate would not have any thermal stress. Nucleation side would only possess the stress due to the presence of growth defects. And, it is very obvious that the nucleation side would have growth defects which are typical for initial growth and nucleation period of the CVD run. Now W13 and W14 were also grown for less number of hours, so it may be expected that they would also possess the similar growth defects which are typical of initial growth and nucleation period of the CVD run. The identical stress values of W11, W13 and W14 indicate that they had similar kind of CVD growth defects responsible for the identical tensile stress of 2.4 GPa. On the other hand, W23 was deposited for $25.5 \mathrm{~h}$, producing quite a thick coating, which not only had the presence of growth defects from initial nucleation period of the CVD run, but also it had additional number of defects which increased the total down shift of the Raman peak and thereby the intrinsic tensile stress went up to $3 \mathrm{GPa}$.

\subsection{Tribological study}

3.2a Wear and friction data: In tribological tests, the PCD surface of high asperities and low valleys was in sliding 

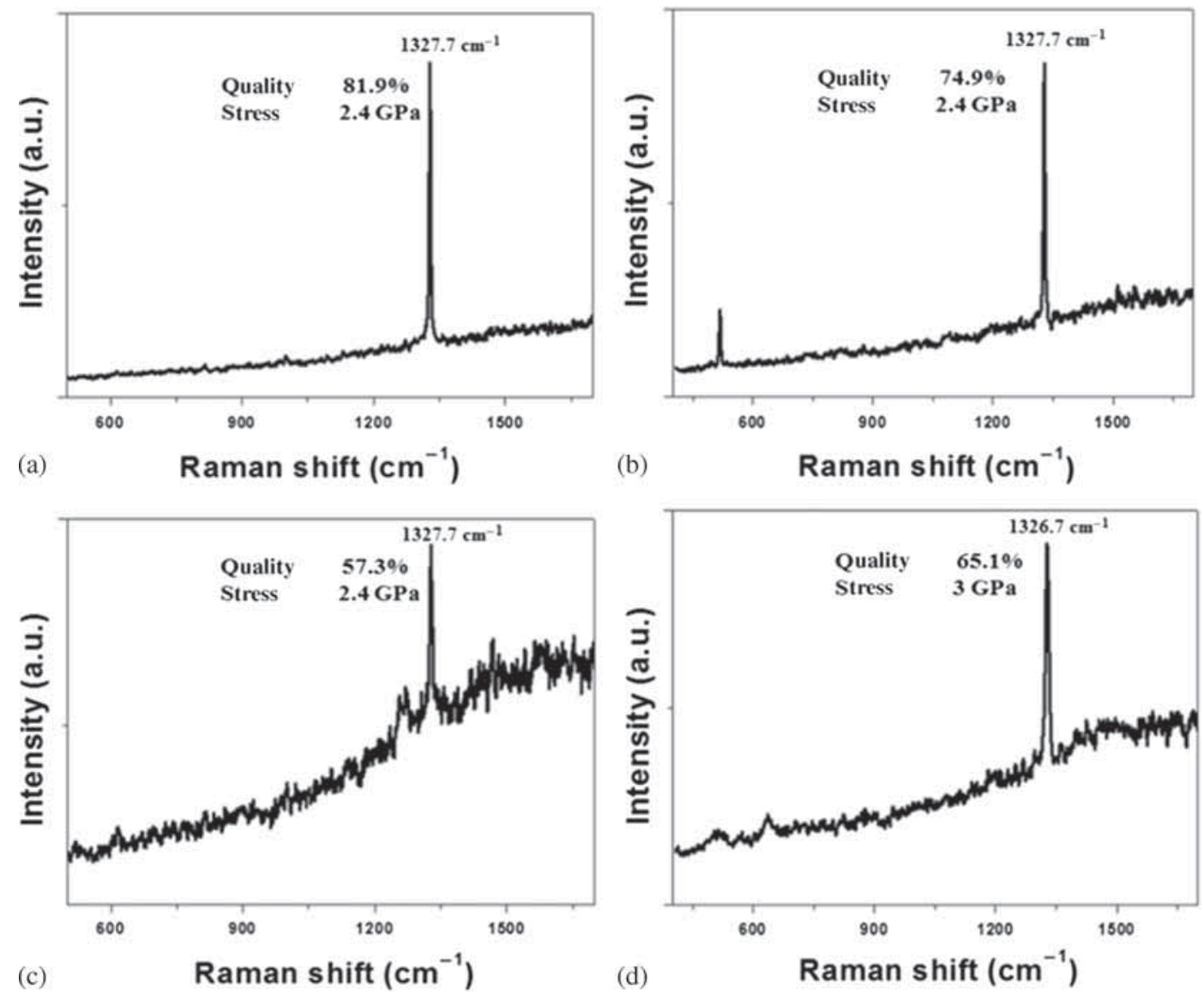

Figure 1. Raman spectra of (a) W11, (b) W14, (c) W13 and (d) W23 samples.

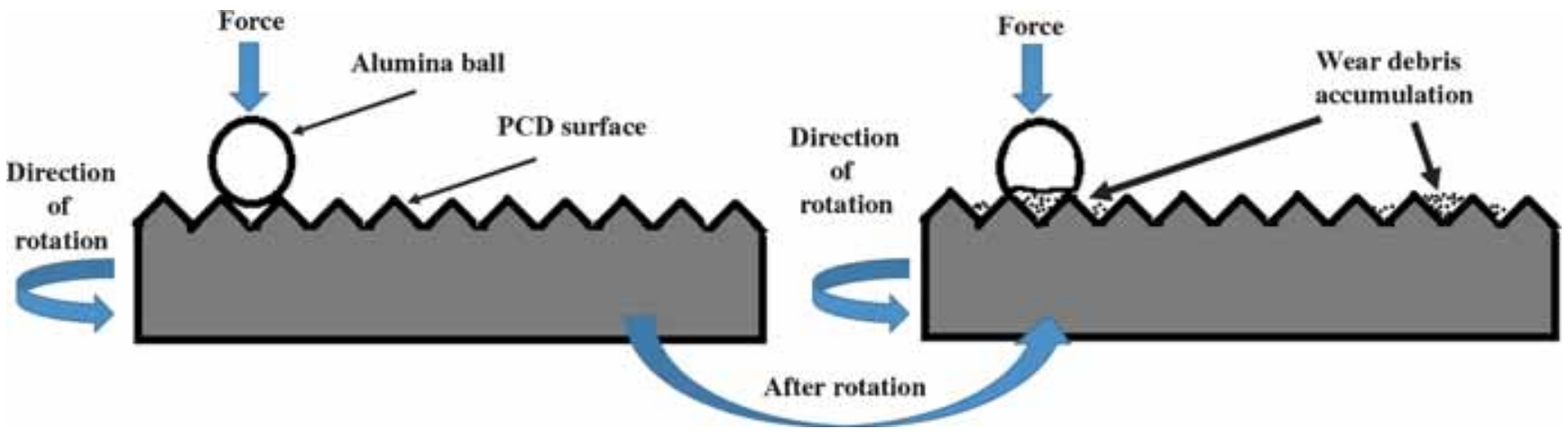

Figure 2. Schematic of wear mechanisms of alumina ball on the PCD surface.

motion, and the alumina ball came in direct contact with the high asperities of the PCD surface, where microscopic wear takes place (figure 2). The coefficient of friction was high at the beginning of the experiments due to static friction and after a certain time period it reduces to lower values due to dynamic friction. Friction curves are shown in figure 3.

For the experiments with 3-mm diameter alumina ball, the maximum or initial Hertzian contact pressure $\left(P_{\mathrm{o}}\right)$ is calculated using the below equation:

$$
P_{\mathrm{o}}=\left(6 W E^{* 2} / \pi^{3} R^{2}\right),
$$

where $W$ is the applied load in Newton, $E^{*}$ is effective elastic modulus and $R=0.0015 \mathrm{~m}$ is the radius of the ball. $E^{*}=(1-$ $\left.v_{1}^{2}\right) / E_{1}+\left(1-v_{2}^{2}\right) / E_{2}=247 \mathrm{GPa}$, where $v_{1}=0.27$ and $v_{2}=$ 0.2 are the Poisson's ratios, and $E_{1}=300 \mathrm{GPa}$ and $E_{2}=$ $1000 \mathrm{GPa}$ are the elastic modulus of alumina and diamond, respectively. Estimation of $P_{\mathrm{o}}$ would give an idea about the amount of stress at the beginning and would correlate with the severity of wear on alumina by diamond (table 4). $1 \mathrm{~N}, 2 \mathrm{~N}, 3 \mathrm{~N}$ and $5 \mathrm{~N}$ loads produce systematic rise in initial Hertzian contact pressures from 5.2, 10.5, 15.7 to $26.2 \mathrm{GPa}$, respectively. 


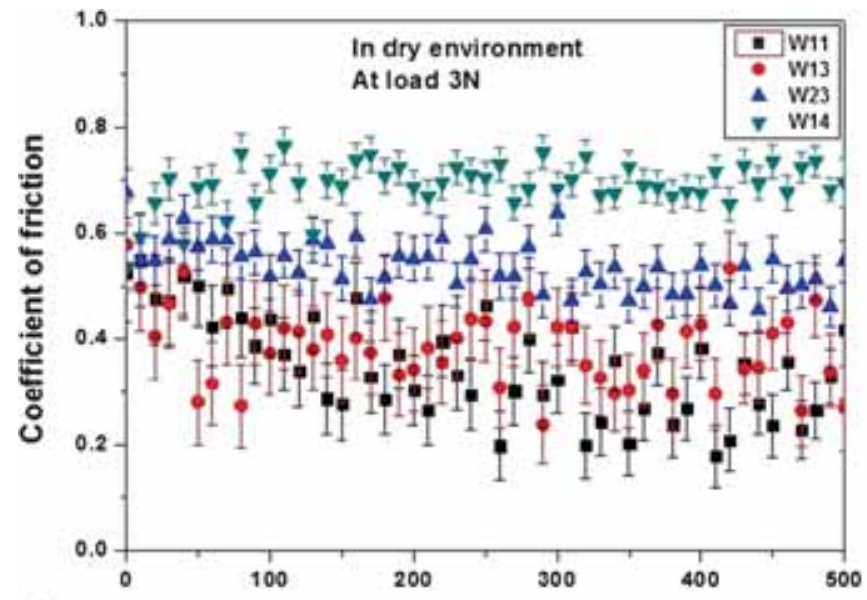

(a)

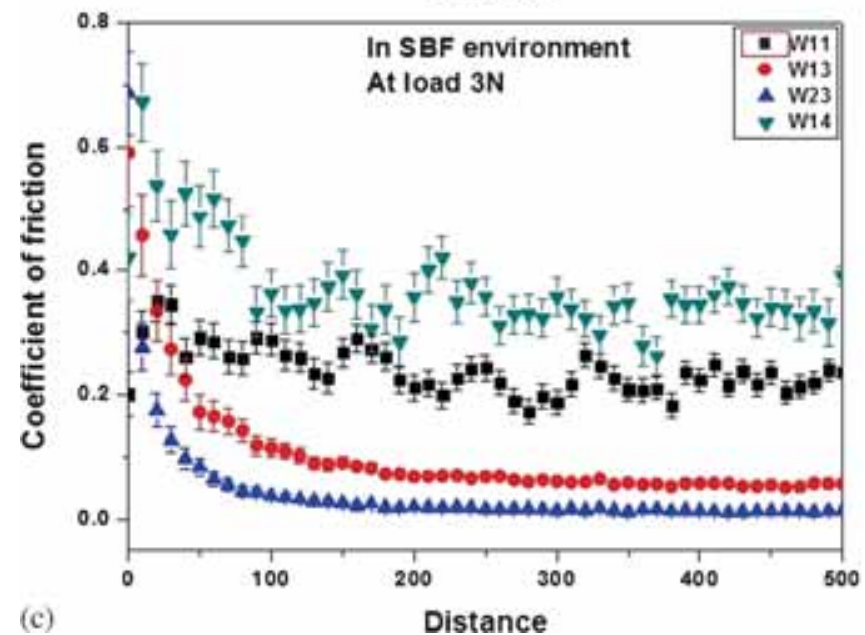

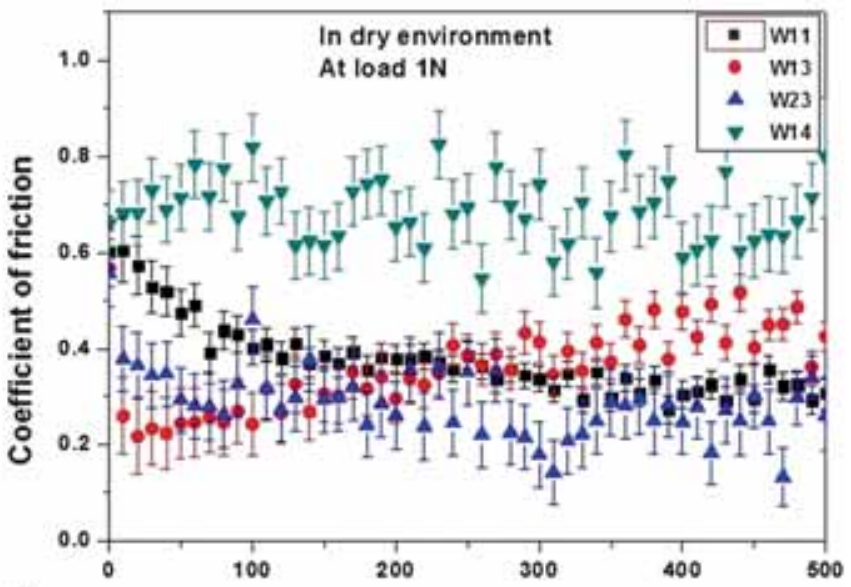

(b)

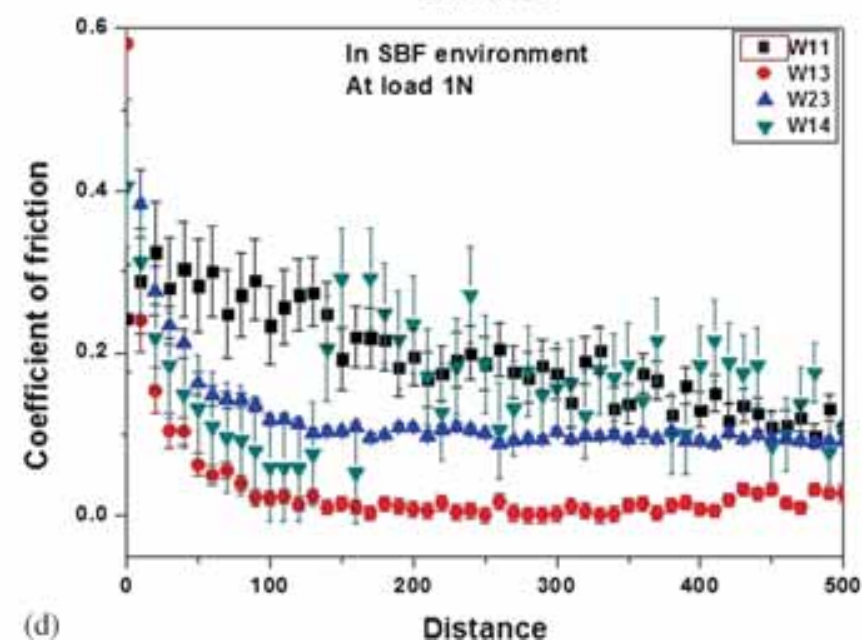

Figure 3. Friction curves of W11, W13, W14 and W23 (a) at $3 \mathrm{~N}$ and (b) $1 \mathrm{~N}$ load in dry environment and (c) at $3 \mathrm{~N}$ and (d) $1 \mathrm{~N}$ load in SBF environment.

Table 4. Wear and friction data of PCD samples.

\begin{tabular}{|c|c|c|c|c|c|c|c|c|}
\hline \multirow[b]{2}{*}{ Sample name } & \multicolumn{4}{|c|}{ Dry environment } & \multicolumn{4}{|c|}{ SBF environment } \\
\hline & Load $(\mathrm{N})$ & $\mathrm{COF}$ & $\begin{array}{l}\text { Wear volume } \\
\left(\mathrm{mm}^{3}\right)\end{array}$ & $\begin{array}{c}\text { Wear rate } \\
\left(\mathrm{mm}^{3} \mathrm{Nm}^{-1}\right)\end{array}$ & Load $(\mathrm{N})$ & $\mathrm{COF}$ & $\begin{array}{l}\text { Wear volume } \\
\qquad\left(\mathrm{mm}^{3}\right)\end{array}$ & $\begin{array}{c}\text { Wear rate } \\
\left(\mathrm{mm}^{3} \mathrm{Nm}^{-1}\right)\end{array}$ \\
\hline W11 & 3 & 0.34 & $1.34 \times 10^{-2}$ & $8.97 \times 10^{-6}$ & 3 & 0.23 & $8.47 \times 10^{-4}$ & $5.63 \times 10^{-7}$ \\
\hline W11 & 1 & 0.37 & $3.52 \times 10^{-3}$ & $7.05 \times 10^{-6}$ & 1 & 0.19 & $2.4 \times 10^{-4}$ & $4.82 \times 10^{-7}$ \\
\hline W13 & 5 & 0.38 & 1.068 & $4.17 \times 10^{-4}$ & 3 & 0.09 & 2.66 & $1.76 \times 10^{-3}$ \\
\hline W13 & 2 & 0.35 & 0.0762 & $7.63 \times 10^{-5}$ & 1 & 0.03 & 0.377 & $7.54 \times 10^{-4}$ \\
\hline W14 & 3 & 0.68 & 0.332 & $2.22 \times 10^{-4}$ & 3 & 0.36 & 3.75 & $2.5 \times 10^{-3}$ \\
\hline W14 & 1 & 0.7 & 0.174 & $3.48 \times 10^{-4}$ & 1 & 0.14 & 0.964 & $1.92 \times 10^{-3}$ \\
\hline W23 & 3 & 0.52 & 1.94 & $1.29 \times 10^{-3}$ & 3 & 0.03 & 2.24 & $1.49 \times 10^{-3}$ \\
\hline W23 & 1 & 0.29 & 1.094 & $2.18 \times 10^{-3}$ & 1 & 0.12 & 0.94 & $1.88 \times 10^{-3}$ \\
\hline
\end{tabular}

COF values depend on the applied load (contact pressure) and the sliding contacts of the counter bodies with interacting surfaces. With increase in the load (or Hertzian pressure) and the change of sliding contacts, COF also changes. In figure $3 \mathrm{a}$ and table 4, the friction curve of sample W14 demonstrates the highest COF values under dry environment at the applied load of $3 \mathrm{~N}$ and the friction curves of remaining samples W23, W13 and W11 show decreasing COF values with decrease of their roughnesses. In the dry environment at $1 \mathrm{~N}$ load (figure 3b), W14 shows the highest COF but W23 sample shows the lowest COF though it has the highest roughness. In the $\mathrm{SBF}$ environment at $3 \mathrm{~N}$ load (figure $3 \mathrm{c}$ ), W14 sample shows the highest COF value though the sample had the lowest roughness and W23 shows the lowest COF value though it has the highest roughness value. W11 sample shows higher COF in SBF environment at $1 \mathrm{~N}$ load (figure $3 \mathrm{~d}$ ). 
W14 sample also shows higher COF during run-in time period at $1 \mathrm{~N}$ load though it had lower roughness than the asgrown samples. W23 shows higher COF value than W13 at $1 \mathrm{~N}$ load in SBF. The trend in COF cannot be fully explained by the roughness data only for the PCDs. COF appears to be affected by the quality and internal stress of the deposited coatings as well. W11 and W14 are the best quality PCDs, whereas W13 is the worst one. On the other hand, W11, W14 and W13 have identical internal stress, whereas W23 has somewhat greater tensile stress.

Table 4 shows that W14 sample has the highest COF value in dry and SBF environments with the applied load of $1 \mathrm{~N}$ and $3 \mathrm{~N}$, though its surface roughness was lower than the other as-grown PCD samples. It may be due the Si base substrate effect as W14 was deposited only for $7 \mathrm{~h}$ duration with $1 \%$ methane, which could deposit a thin diamond coating and after polishing it might had reduced to a very thin coating. According to Holmberg and Matthews [47] if the diamond coating was very thin then its base substrate had some significant effect on COF and as well as in wear. It is well known that bare Si has more COF than PCD and the base substrate may have influenced the sliding behaviour of alumina over PCDcoated sample W14. Moreover, the quality of W14 was found to be high, which might be responsible for its high COF. In dry environment W11 and W13 samples show comparatively almost similar COF values, although the roughness of W13 sample was higher than W11 and also its quality (figure 1) was much inferior. Mallik et al [48] observed that Si is present in the intergranular region, as well as Si may be bonded with carbon atoms present on the PCD backside. In effect, the nucleation side of W11 is not a pure diamond, rather it is a microstructure with agglomerated nano-crystalline diamond having many non-diamond phases present (more detailed elemental analysis is done in sub-section 3.2d). But if we discuss purity, figure 1 shows Raman signals are the strongest for W11 nucleation side. So there must be some other factor responsible for similar COF. Samples were deposited on silicon wafer, so there might be silicon carbide or silicon impurities on the nucleation side and their presence can affect the tribological behaviour of the PCD coatings.

W13 sample gives higher COF value at $2 \mathrm{~N}$ load than W23 sample at $1 \mathrm{~N}$ load in a dry environment, as the COF depends very much on the applied load. In dry environment at $3 \mathrm{~N}$ load, W23 gives higher COF than W13, though applied load was higher for W13, i.e., 5N. This high COF was observed since the W23 sample had higher surface roughness than W13.

COF values of the samples were lower in SBF environment, as SBF solution gave some lubricating effect under sliding contact. From the literature it is known that water has some lubricating effect on the nano-crystalline diamond coating and reduces the COF value [49]. SBF solution also contains water, so in effect this solution may reduce the COF value. Again, it is observed that the W11 and W14 samples give higher COF in SBF environment at both the applied loads than the as-grown samples W13 and W23 (may be because of higher $Q$-factors as shown in figure 1 ).
W23 shows low COF at 3N load compared to W13 sample, whereas at $1 \mathrm{~N}$ load W23 shows higher COF than W13, as W23 had higher roughness. When a diamond hard surface is sliding against a comparative softer material, the softer material wears out and fills the asperities of rough diamond surface and reduces its friction levels [50]. Correspondingly, $\mathrm{COF}$ value also decreases as the friction level reduces. Lower COF was found for W23 sample at a higher load of $3 \mathrm{~N}$, which might be because the sample had the highest roughness and thereby generated more wear debris which filled the valleys of the sample surface.

3.2b Wear observed under optical microscope: After the tribology experiments, the worn out alumina balls and the PCD surfaces were observed under the optical microscope. From the optical microscope pictures of alumina balls, wear volume and wear rate of alumina were calculated (table 4). Optical microscope pictures of the wear tracks on the PCD surfaces and their corresponding worn out alumina balls (inset) are shown adjacent to each other for each experiments in figure $4 \mathrm{a}-\mathrm{p}$. Under each condition, two set of loads were applied, corresponding to wear tracks of the inner and outer radii, which thereby are for lower and higher loads, respectively.

Alumina ball (19 GPa) was less hard than PCD surfaces (>40 GPa), so when it was rubbed against PCD, it happened to wear out. Wear volume of alumina ball was also increased with the increase of applied load under identical test environments. Nucleation side of W11 sample had very smooth surface and so when alumina was rubbed against that surface, very small amount of wear particles were generated in both the dry and SBF environments. In dry ambient condition, wear debris generation was slightly higher than in SBF environment. SBF acted as a lubricant and formed a very thin liquid surface between alumina ball and the PCD coatings, reducing COF values as well as the wear volume of alumina. Optical microscope pictures of W11 sample show only wear marks on PCD surface (figure $4 \mathrm{a}-\mathrm{d}$ ). Diameters of the alumina balls after wear were also smaller under SBF environment (inset images of figure $4 \mathrm{c}$ and $\mathrm{d}$ ), which indicate low wear volume of the balls. W13, W14 and W23 samples had relatively higher roughness than W11 sample, and the experiment was done on the growth surface of those samples. When the experiment was done on the growth surface of PCD coating, it was observed that the wear of alumina was facilitated and the wear volume was increased (inset images of figure $4 \mathrm{e}-\mathrm{p})$. The optical images of wear tracks under SBF environment (figure 4g, h, k, 1, o and p) show lighter whitish stains, but the optical images of wear tracks under dry environment show deeper whitish stains (figure 4e, f, i, j, m and n). The whitish stains may be due to wear debris accumulation. Under dry condition, wear debris was piled up on the wear tracks while in SBF condition wear debris accumulation was apparently less, since the generated wear particles might get dissolved and been washed away by the liquid environment. The accumulated wear debris may be the reason of higher COF (more resistance under sliding contact) value in dry 
conditions. In SBF condition, wear debris formed in the wear track was wiped out from the track, facilitating the alumina ball to come again in contact with fresh PCD-coating surface, which might have caused more wear of alumina balls. W13 and W23 samples show slightly more amount of wear debris present on the wear tracks at $1 \mathrm{~N}$ load (figure $4 \mathrm{~g}$ and o) than at $3 \mathrm{~N}$ load (figure $4 \mathrm{~h}$ and $\mathrm{p}$ ), under SBF conditions. In table 2, it is shown that at $1 \mathrm{~N}$ load rpm value was much higher than rpm value at $3 \mathrm{~N}$ load. So it might be the case that the wear debris could not be washed out properly by SBF at higher rpm value (analogy may be drawn to the phenomenon of seeing white colour when seven colours of a wheel is rotating at very high speed). Wear particles could be washed out more frequently at lower rpm ( $3 \mathrm{~N}$ load), resulting in accumulation of less amount of wear debris.

Figure 5 is a description of alumina ball's wear rate with variation of the PCD discs in the different experimental environment. The PCD coatings are different from each other in respect of their roughness and quality. It is to be noted that as we move from the as-grown PCD to chemo-mechanically polished PCD, the surface becomes smoother. Nucleation side of the deposited diamonds is the smoothest. On the other hand regarding their quality, the diamond samples can be ranked as $\mathrm{W} 11>\mathrm{W} 14>\mathrm{W} 23>\mathrm{W} 13$, with decreasing order in their $Q$-factor. Since the diamond surface appears not to wear, it can be stated that their individual quality is very high for them to wear out under sliding action. Here all the wear data are for the loss of alumina material from the counter ball body. The severity of the wear is primarily governed by the roughness of the PCD counter-face. Since the alumina balls used in all the tribological experiments are identical, their wear data will be identified with the wafer number used in each experiment.

It is observed that for all the respective values, W11 has the lowest wear rate data, which may be due to its very low surface roughness. Such low value of surface roughness is because it is the nucleation side of the PCD coating. In the presence of lubricant (SBF), W14 has the highest wear rate, which may be due to its less thickness, giving rise to base substrate effect [47]. On the other hand in the dry environment, it is observed that W23 has the highest wear rate data. W23 has the highest roughness among all the samples, which is responsible for the highest wear volume generation at the dry environment. Therefore, it may be that the SBF is responsible for reversing the trend in wear rate generation for W14 and W23, i.e., the highest wear data. W23 has higher

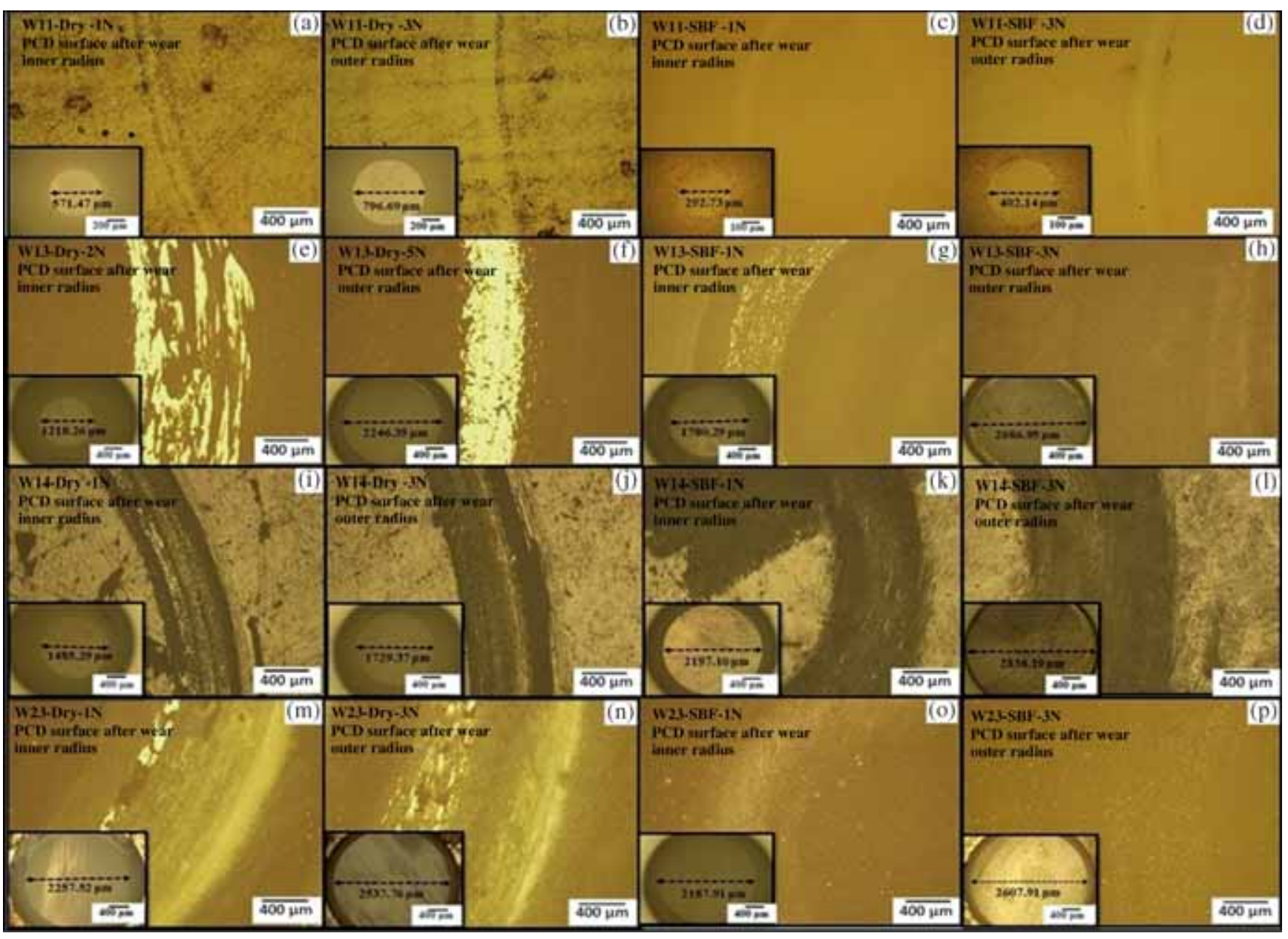

Figure 4. Optical microscope images of the wear tracks on PCD surfaces with the inset images of the worn out alumina balls. 


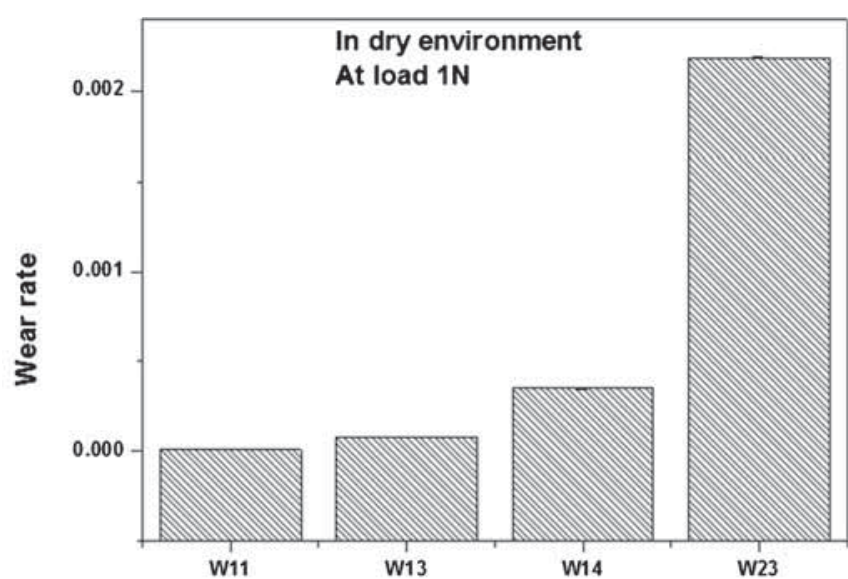

(a)

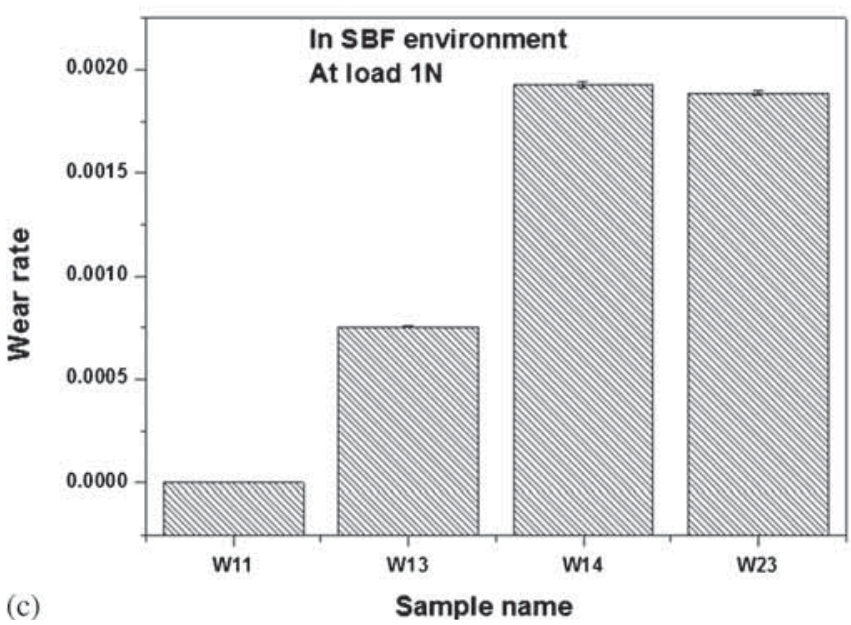

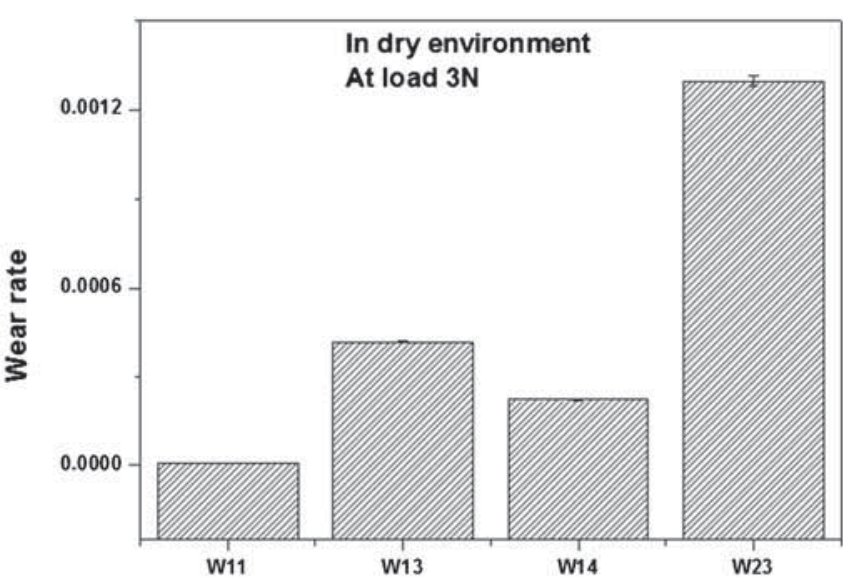

(b)

Sample name

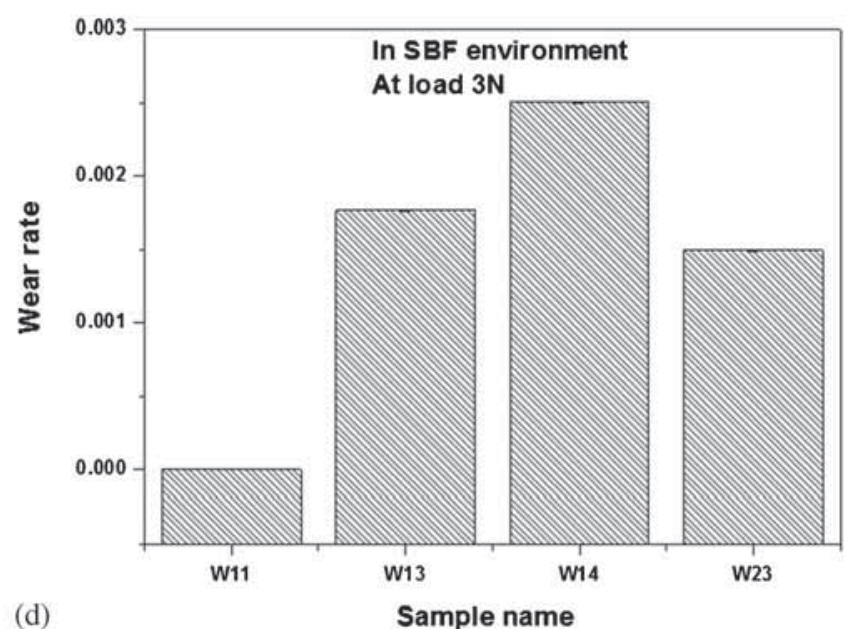

Figure 5. Wear rate of W11, W13, W14 and W23 (a) at $3 \mathrm{~N}$ and (b) $1 \mathrm{~N}$ load in dry environment and (c) at $3 \mathrm{~N}$ and (d) $1 \mathrm{~N}$ load in $\mathrm{SBF}$ environment.

roughness and better $Q$-factor than $\mathrm{W} 13$, so its wear rate was always higher except under SBF at $3 \mathrm{~N}$ load. The exception can be explained as follows: the wear debris generated faster for W23 than W13 to fill its asperities and, as a result COF value decreases to generate less wear rate for W23 than W13.

3.2c Wear observed under SEM: Wear morphology of the PCD surfaces are explained by SEM images in figure 6 and the inset images of PCD wear tracks at lower magnifications alongside are also shown. The direction of sliding movement was indicated by double-headed arrows in figure 6. SEM picture reveals that PCD crystals do not wear rather it gets covered with alumina wear debris. The wear debris was found to be compacted or loose, depending on the experimental environment. Diamond surface was five times harder $(\sim 100 \mathrm{GPa})$ than the alumina counterbody ( $\sim 20 \mathrm{GPa})$, so from the tribology experiment we get the expected result that most of the alumina ball was worn out and in few cases only some cracks (figure $6 \mathrm{a}-1$ ) on the diamond-coated surface were observed under SBF condition, which at higher magnifications was found to be the dried out alumina wear debris. Figure $6 \mathrm{a}$ shows the SEM image of sample W11. At the lowest magnification level (show in the inset image of figure 6a), clear circular wear mark is visible. Such lowest magnifications have been provided in most of the SEM images of figure 6 , to understand better the circular wear tracks that were developed during the present series of tribological experiments. A portion of such circular wear tracks was further magnified in each case to observe a section of it, which again is shown in the inset of figure 6. Further magnification of such sectional wear arcs reveals detailed microstructure of the wear regions, as depicted in enlarged figure 6. Such successive higher magnified images are shown by arrows in figure 6. SEM picture of W11 sample (inset figure 6a) shows some white wear debris on the outer radius ( $3 \mathrm{~N}$ load) of the sample, and at higher magnification some white patches along with black spots are also observed. There was no significant wear debris found on the wear track of the hard nucleation side of the PCD coatings. Some black spots were shown on the surface, which may be due to amorphous carbon, $\mathrm{sp}^{2}$ carbon impurities (figure 6a). W13 sample shows full surface coverage with white wear debris on the outer wear tracks at higher magnification in dry condition and adjacent to the white wear debris blackish PCD crystals were 

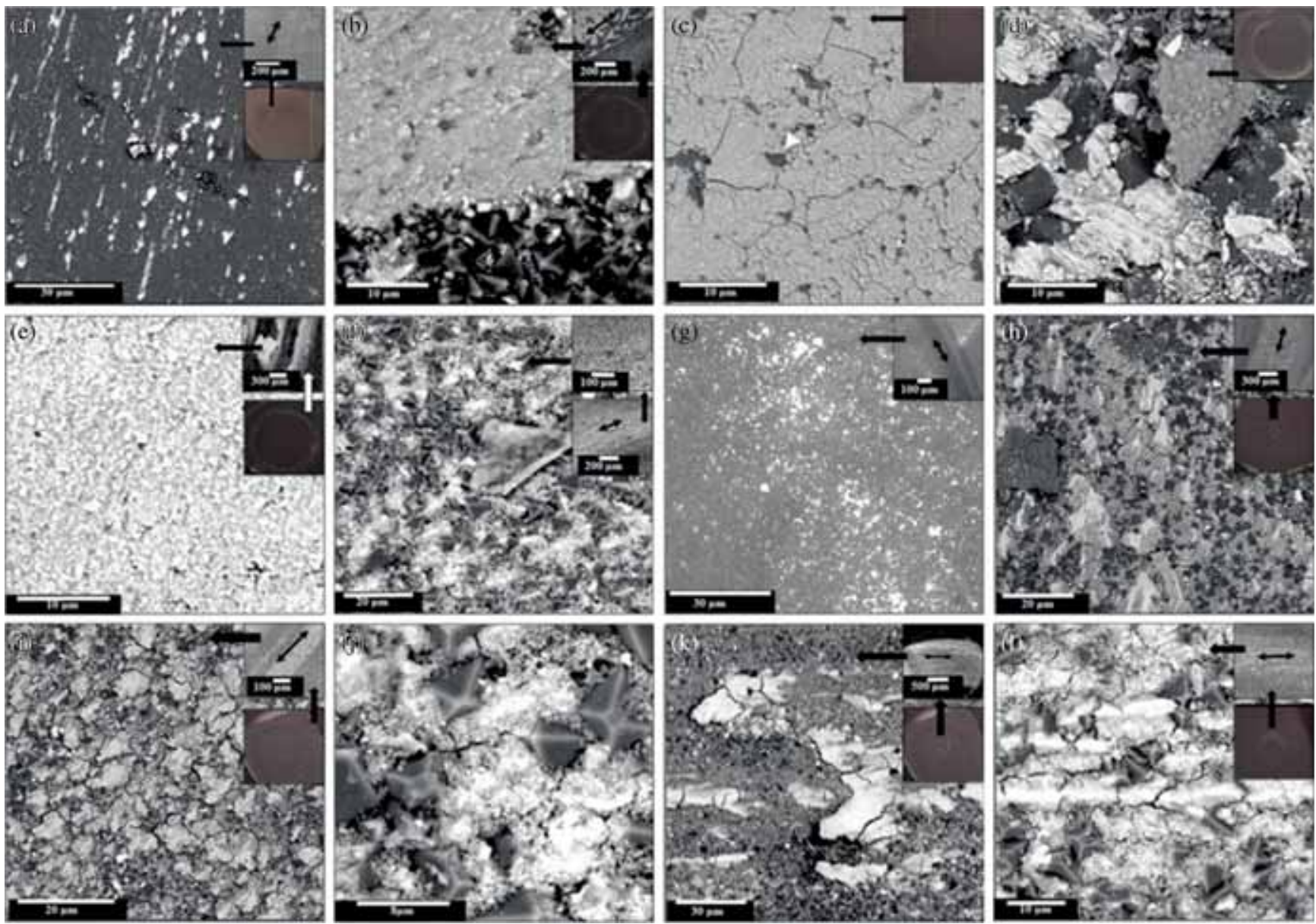

Figure 6. SEM images of wear track with different magnification (a) W11, (b), W13, (c) W14 and (d) W23 at 3N load and (e) W13, (f) W23 at 1N load under dry environment; (g) W11, (h) W13, (i) W14, (j) W23 at 3N load and (k) W14, (l) W23 at 1N load under SBF environment.

found (figure 6b). It was clearly observed that PCD surface does not wear at all with the presence of perfectly shaped diamond polyhedrals and the adjacent white patch may be due to alumina ball (will be confirmed from EDX). W14 sample shows complete white wear debris coverage on the outer wear track at higher magnification, and very few black spots were visible which are due to protruding diamond crystals (figure 6c). The SEM picture at higher magnification of the outer track of W23 sample clearly shows that the wear debris fills the valleys, and the PCD polyhedrals remain unaffected during sliding action of alumina balls (figure 6d).

SEM images of W13 sample on inner radius (1N load) also show wear debris on the tracks and increasing the magnification at a particular area shows complete coverage of PCD surface with white wear debris and the diamond polyhedrals were not visible (figure 6e). Inner wear track of W23 sample (figure 6f) shows similar surface morphology like the outer track of W23 in a dry environment (figure 6d).

SEM image of W11 sample in SBF condition shows that wear debris were washed out from the wear track and were got accumulated on the wear track periphery (figure 6g). W13 and W23 are as-grown samples and their rough surface contains many crystal asperities. The SEM images of W13 and
W23 samples, at both the applied loads in SBF, show similar surface characteristics, where whitish alumina wear debris fills the low valley areas in between surface asperities and the PCD crystals are protruding out from here and there (figure $6 \mathrm{~h}$, $\mathrm{j}$ and 1 ). Some cracks are observed inside the wear debris filled areas and from the SEM images it was clearly found that the cracks were not across the diamond crystals. These cracks may be generated due to drying out of wear debris which formed paste under SBF condition. W14 sample was deposited for $7 \mathrm{~h}$, so its PCD crystal sizes were small, and it was also chemo-mechanically polished, so that the high troughs were flattened out. Their SEM images show many cracks on the dried out wear debris with diamond polycrystals scattered around in wear debris matrix (figure $6 \mathrm{i}$ and $\mathrm{k}$ ).

$3.2 \mathrm{~d}$ Elements present on the wear tracks-EDX analysis: Elemental analysis of the wear tracks on the surfaces of different microwave plasma enhanced chemical vapour deposited samples were studied to understand better the chemical nature of the whitish layers and the black polyhedrals visible under SEM. Figure 7a and b, respectively, represents the area elemental EDX beside and inside the wear 

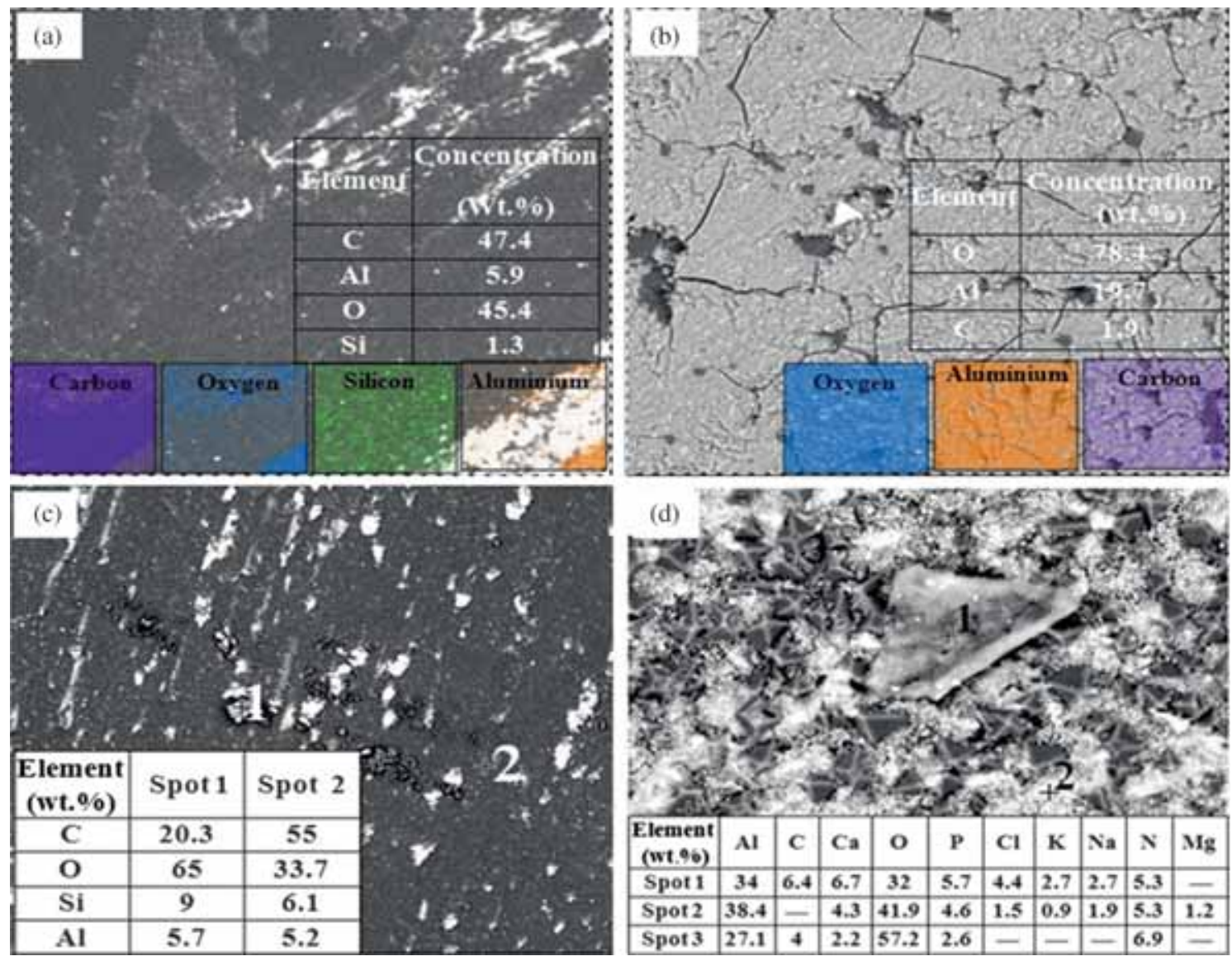

Figure 7. EDAX area scans of (a) W14 (beside wear track) and (b) W14 (inside wear track); point scans of (c) W11 and (d) W23 inside wear track.

track at the dry environment for W14. The point EDX at dry and SBF environment was shown for the samples W11 and W23 in the figure 7c and d, respectively. Wear track/marking was generated due to the friction of alumina ball with the hard diamond surface. The higher amount of debris was found with increasing roughness of the diamond sample. The quality of each PCD coating ensured that there is enough $\mathrm{sp}^{3}$ phase present for the coating not to wear out, rather it caused the softer alumina counter-body to wear severely. EDX study of figure 7a proves the wear of alumina ball, as the elemental analysis of wear debris shows a certain amount of aluminium, which comes from the ball only. However, most of the element present was carbon in the PCD surface region of figure 7a. W14 sample had highest COF value though its roughness was lower than other two as-grown samples due to Si substrate effect. The area elemental analysis of the W14 PCD coating adjacent to the wear track shows 1.3 weight percentage of silicon (figure 7a). It might have come from $\mathrm{Si}$ substrate, because the deposition time of W14 sample was $7 \mathrm{~h}$ only, so the coating thickness was very low. In figure $7 \mathrm{~b}$, white patches were seen on the wear track of W14 sample and the area EDX analysis shows higher weight percentages of aluminium and oxygen present, than carbon. Therefore, from the EDX analysis, it was confirmed that white wear particles were generated from alumina counter face. The surface roughness was lowest for the nucleation side of W11, but its COF value was high and comparable with the asgrown sample W13. From the point EDX analysis of W11 nucleation side it was evident that both the spots contain little weight percentage of silicon (figure 7c), as the base substrate was silicon and this silicon might be in carbide form. High COF value of $\mathrm{W} 11$ can be attributed due to the presence of silicon on the smooth nucleation side. In both the spots of figure $7 \mathrm{c}$, aluminium was found, so it is again evident that the alumina ball was mainly worn out. Figure $7 \mathrm{~d}$ denotes the SEM image of the wear track of W23 in SBF condition and its point EDX analysis at two different points. EDX data show the presence of different elements which came from the SBF solution. Spots 1 and 3 in figure $7 d$ show little amount of carbon, which comes from the diamond surface. Spot 2 shows no carbon as this area was full of white alumina wear debris.

\section{Conclusions}

Researchers are in the quest of new biomaterials, which can replace the existing options available for the load-bearing implants. The problem lies in the generation of the wear debris inside human body from these implants. Aluminaalumina articulating implants are the best known low-wear 
prosthetic material available today, but lower values of COF (0.03) and zero wear indicate that the PCD ceramic coating grown by MWCVD process can be used as articulating surfaces for bio-tribology. Present experiment shows severe wear $\left(2.5 \times 10^{-3} \mathrm{~m}^{3} \mathrm{Nm}^{-1}\right)$ of alumina balls sliding against hard (>40 GPa) diamond ceramic coatings. Apart from better tribological behaviour, ceramic coating has the advantage over the bulk failure of brittle alumina ceramics in loadbearing implant application. In tribology industry, alumina plays an important role but the use of PCD coatings may be more practical to increase the machine life as well as the longevity of bio-implants. Very smooth nucleation side $(0.12 \mu \mathrm{m})$ of the diamond surface produced very low amount of wear debris $\left(2.4 \times 10^{-4} \mathrm{~mm}^{3}\right)$ for the alumina ball, and the wear rate was found to be very low $4.82 \times 10^{-7} \mathrm{~mm}^{3} \mathrm{Nm}^{-1}$. Therefore, the smoothness of the PCD surface is also one of the requirements to decrease the wear and thereby to increase the machine life. Further experiments are underway for evaluating the biocompatibility of PCD coatings. Here we could show that diamond coating is better bio-ceramic material than bulk alumina ceramics from tribological perspective.

\section{Acknowledgements}

The financial support was from $12^{\text {th }}$ Five Year Plan CSIR network project MTDDC, PSC0101 and DST sponsored IndoRussian S\&T program GAP0246. We thank Directors of NIT, Durgapur, and CSIR-CGCRI for permitting to carry out the present research work.

\section{References}

[1] May P W 2000 Philosophical Transactions of the Royal Society A 358473

[2] Bhushan B, 2001 (Boca Raton, Florida: CRC Press LLC) Vol 1 and 2

[3] Gao G, Cannara R J, Carpick R W and Harrison J A 2007 Langmuir 235394

[4] Gao G T, Mikulski P T and Harrison J A 2002 J. Am. Chem. Soc. 1247202

[5] Mathew M T, Srinivasa Pai P, Pourzal R, Fischer A and Wimmer M A 2009 Adv. Tribol. 200912

[6] Bandorf R, Paulkowski D M, Schiffmann K I and Küster R L A 2008 J. Phys. Condens. Matter 20354018

[7] Field J E 1992 The Properties of Natural and Synthetic Diamond (London: Academic Press)

[8] Booth L, Catledge S A, Nolen D, Thompson R G and Vohra Y K 2011 Materials 4857

[9] Clem W C, Chowdhury S, Catledge S A, Weimer J J, Shaikh F M and Hennessy K M 2008 Biomaterials 293461

[10] Rezek B, Michalíková L, Ukraintsev E, Kromka A and Kalbacova M 2009 Sensors 93549

[11] Amaral M, Gomes P S, Lopes M A, Santos J D, Silva R F and Fernandes M H 2009 Acta Biomater. 5755

[12] Jakubowski W, Bartosz G, Niedzielski P, Szymanski W and Walkowiak B 2004 Diam. Relat. Mater. 131761
[13] Specht C G, Williams O A, Jackman R B and Schoepfer R 2004 Biomaterials 254073

[14] Wood R J K, Surface Engineering and Tribology Group, University of Southampton, SO17 1BJ, UK

[15] Miyoshi K, National Aeronautics and Space Administration, Lewis Research Center, NASA Technical Memorandum 106759

[16] Bull S J 1995 Diam. Relat. Mater. 4827

[17] Liu E, Blanpain B and Celis J P 1996 Diam. Relat. Mater. 5 649

[18] Abreu C S, Amaral M, Fernandes A J S, Oliveira F J, Silva R F and Gomes J R 2006 Diam. Relat. Mater. 15739

[19] Xinchun C, Zhijian P, Xiang Y, Zhiqiang F, Wen Y and Chengbiao W 2011 Appl. Surf. Sci. 2573180

[20] Erdemir A, Fenske G R, Krauss A R, Gruen D M, Mccauley T and Csencsits R T 1999 Surf. Coat. Technol. 120565

[21] Plano L S, http://www.dtic.mil/dtic/tr/fulltext/u2/a220265. pdf, last accessed on 16 July 2015

[22] Takeno T, Komoriya T, Nakamori I, Miki H, Abe T, Uchimoto, T and Takagi T 2005 Diam. Relat. Mater 142118

[23] Mallik A K, Shivashankar S A and Biswas S K 2009 Sadhana 34811

[24] Bhushan B, Subramaniam V V, Malshe A, Gupta B K and Juai R 1993 J. Appl. Phys. 744174

[25] Luo Shenq Y, Kuo Jui K, Brian Y, Sung James C, Dai Chuang W and Tsai T J 2001 Mater. Chem. Phys. 72133

[26] Skopp A and Klaffke D 1998 Surf. Coat. Technol. 981027

[27] Grögler T, Franza A, Klaffke D, Rosiwal S M and Singer R F 1998 Diam. Relat. Mater. 71342

[28] Mahmud K A H A, Kalam M A, Masjuki H H, Mobarak H M and Zulkifli N W M 2015 Crit. Rev. Solid State Mater. Sci. 40 90

[29] Radhika R, Kumar N, Kozakov A T, Sankaran K J, Dash S, Tyagi A K, Tai N H and Lin I N 2014 Diam. Relat. Mater. 486

[30] Jianyi C and Xipeng X 2014 Int. J. Adv. Manuf. Technol. 71 1579

[31] Mallik A K, Bysakh S, Dutta S and Basu D 2014 Sadhana 39 957

[32] Mallik A K, Pal K S, Dandapat N, Guha B K, Datta S and Basu D 2012 Diam. Relat. Mater. 3053

[33] MaJ, PhD Thesis, 2008 University of Bristol, Department of Chemistry 21

[34] Timothy G, Asmussen J, Asmussen J, D K Reinhard (eds.), 2002 Diamond Films Handbook, Chapter 7

[35] Cheng C Y, Tsai H Y, Wu C H, Liu P Y, Hsieh C H and Chang Y Y 2005 Diam. Relat. Mater. 14622

[36] Thomas E L H, Nelson G W, Mandal S, Foord J S and Williams O A 2014 Carbon 68473

[37] Mallik A K, Bysakh S, Pal K S, Dandapat N, Guha B K, Datta S and Basu D 2013 Indian J. Eng. Mater. Sci. 20522

[38] Bergman L and Nemanich R J 1996 Annu. Rev. Mater. Sci. 26 551

[39] Yoshikawa M, Katagiri G, Ishida H, Ishitani A, Ono M and Matsmura K 1989 Appl. Phys. Lett. 552608

[40] Hayes W and Loudon R 1978 (New York: Wiley)

[41] Pickard C D O, Davis T J, Wang W N and Steeds J W 1998 Diam. Relat. Mater. 7238 
[42] Erasmus R M, Comins J D, Mofokeng V and Martin Z 2011 Diam. Relat. Mater. 20907

[43] Nibennanoune Z, Georg D, Antoni F, Ahzi S, Ruch D, Gracio J and Remond Y 2012 Diam. Relat. Mater. 22105

[44] Ali N, Neto V F, Mei S, Cabral G, Kousar Y, Titus E, Ogwu A S, Misra D S and Gracio J 2004 Thin Solid Films 469 154

[45] Mallik A K, Dandapat N, Chakraborty S, Mandal A K, Ghosh J, Unnikrishnan M, Bysakh S and Balla V K 2014 Proc. Appl. Ceram. 869
[46] Johnston C, Crossley A, Jones A M, Chalker P R, Cullen F L and Buckley-Golder I M 1991 J. de Physique IV 02931

[47] Holmberg K and Matthews A 1994 Coatings TribologyProperties, Techniques and Applications in Surface Engineering (Amsterdam: Elsevier) Chapter 1

[48] Mallik A K, Mendes J C, Rotter S Z and Bysakh S 2014 Adv. Ceram. Sci. Eng. 336

[49] Abreu C S, Amaral M, Oliveira F J, Gomes J R and Silva R F 2009 Diam. Relat. Mater. 18271

[50] Persson B N J 1998 Nanosci. Technol. Series 92 